\title{
A Study of Counselors' Legal Challenges and Their Perceptions of Their ABILITY TO RESPOND
}

\author{
MaRY A. HERMAnN \\ Virginia Commonwealth University \\ Debra GaIl LeGget \\ Indiana State University \\ THEODORE P. REMLEY, JR. \\ Old Dominion University
}

\begin{abstract}
The authors explore the results of a study that assessed the types and frequency of legal issues encountered by counselors and counselors' perceptions of their ability to respond to these issues. They also assessed whether the participants' perceptions were related to practice setting, years of experience, completion of a course in ethics, recent completion of continuing education in ethics or legal issues, state licensure status, certification by the National Board of Certified Counselors (NBCC), and highest degree earned. Results demonstrate that counselors feel most prepared to deal with situations encountered most often, but that school counselors do not feel as prepared to face most ethical and legal issues.
\end{abstract}

Hermann, M. A., Leggett, D. G. \& Remley, T. P., Jr. (2008). A Study of Counselors' Legal Challenges and Their Perceptions of Their Ability to Respond. International Journal of Education Policy and Leadership 3(5). Retrieved [DATE] from http://www.ijepl.org.

Counselors are encountering a multitude of legal issues in their professional practice (Corey, Corey, \& Callanan, 2003; Fernandez, 1992; Remley \& Herlihy, 2001). Remley and Herlihy noted that malpractice lawsuits against mental health professionals have increased dramatically in recent years. However, there is a paucity of literature on the particular legal concerns of counselors or the prevalence of these legal issues. Moreover, counselors' perceptions of their ability to respond to legal issues have not yet been investigated. In this study, we investigated legal issues such as determining whether to report suspected child abuse, being pressured to verbally disclose confidential information, being asked to turn over confidential records, determining whether a client was suicidal, and being subpoenaed to appear as a witness in a legal proceeding. Going one step further, we examined the counselors' perceptions of their preparedness to respond to these issues and whether these per- ceptions were influenced by the work setting, training in ethical and legal issues through coursework or continuing education, amount of education, licensure status, certification status, and years of experience.

Despite the lack of empirical research on legal issues in counseling, numerous journal articles and references in textbooks discuss areas of counselors' legal vulnerability. Corey et al. (2003) and Remley and Herlihy (2001) noted that disclosing confidential information about clients can result in legal liability. Failing to report suspected child abuse can result in civil and criminal liability (Lawrence \& Kurpius, 2000; Remley \& Herlihy, 2001; White \& Flynt, 2000). Failure to warn potential victims of a client's threats of violence and failure to act reasonably in order to prevent a client's suicide can also result in malpractice lawsuits (Ahia \& Martin, 1993; Corey, et al., 2003; Glosoff, Herlihy, \& Spence, 2000; Remley \& Herlihy, 2001).

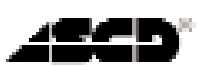


Although few researchers have investigated counselors' confidence with legal challenges, Gibson (1992) examined the similar topic of counselors' knowledge of ethics and confidence in their ethical beliefs, and potentially relevant demographic variables. A statistically significant relationship was found between counselors' knowledge of ethical standards and variables including amount of instruction in ethics, highest degree obtained, and primary practice setting. Gibson also found a significant relationship between counselors' confidence in their ethics beliefs and primary practice setting.

Other studies have focused on school counselors' knowledge of legal issues and potentially relevant demographic variables including training in school law, years of experience in education, memberships in professional organizations, and highest degree earned (Davis \& Mickelson, 1994; Herndon, 1990; Rawls, 1997). According to these studies, school counselors face legal dilemmas in the areas of student privacy, reporting suspected child abuse, counseling students who pose a danger to others, and ensuring the safety of students. Rawls found a significant relationship between school counselors' knowledge of school law and the school counselors' training in school law, membership in professional organizations, and highest degree earned. Both Rawls and Herndon concluded that school counselors were unclear about their legal responsibilities and lack knowledge about state and federal laws that affect their responsibilities as counselors.

\section{Purpose}

The purpose of this study was to determine the prevalent legal issues being encountered by counselors and to examine counselors' perceptions of their ability to respond to these issues. The researchers also considered whether the legal issues being encountered and the prevalence of these legal issues were related to counselors' primary practice settings. Additionally, we explored whether counselors' perceived ability to respond to legal issues was related to primary practice setting, completion of a course in ethics or legal issues in counseling, recent completion of continuing education in ethics or legal issues, highest degree earned, state licensure as a professional counselor, certification by the National Board of Certified Counselors (NBCC), and years of experience as a counselor. The results of this research may inform educational policymakers about the need for training in ethical and legal issues both within counseling programs and in continuing education requirements for practitioners.

\section{Method}

\section{Participants}

Previous research (Gibson, 1992) has indicated a significant relationship between knowledge of ethical standards and confidence in ethics beliefs and primary practice setting (i.e., schools versus community mental health settings). Accordingly, we selected 500 members of the American School Counselor Association (ASCA) and 500 members of the American Mental Health Counselors Association (AMHCA) to participate in this research project. ASCA provided contact information of 500 members selected randomly from the ASCA membership, and AMHCA provided contact information of 500 members selected systematically from the AMHCA membership (every fourth member was selected from an alphabetical list of members). Of the 1,000 surveys distributed, 444 surveys were completed and returned, yielding a response rate of 44 percent. Seven participants indicated that they encountered certain legal issues to an extreme degree (e.g., determining whether a client posed a danger to others 500 times per year). Because the mean is greatly influenced by extreme scores, the responses of these participants were not included in the data analysis.

Sixty-two percent of the respondents indicated that they worked as counselors in school settings. Additionally, 40.5 percent of the respondents were members of AMHCA, 56.8 percent were members of ASCA, and 2.7 percent were members of both organizations. Almost three-fourths (72.9 percent) of the sample were female. The participants identified themselves as African American (5.1 percent), Native American (.7 percent), Hispanic American (2.3 percent), European American (88.3 percent), and Asian American (1.8 percent). In terms of highest degree earned, 82.8 percent of the respondents held a master's degree, 8.5 percent of the respondents held a specialist degree, and 8.5 percent of the respondents had earned a doctorate in counseling. Counselors from every state except Montana and West Virginia responded to the survey. One counselor from the District of Columbia and one counselor from outside of the United States also participated in the study.

The respondents' years of experience as counselors ranged from 1 to 39 , with a mean of $12.52(S D=9.83)$. Consistent with prior research (Rawls, 1997), these data were collapsed into four categories: less than 4 years of experience, 4-7 years of experience, 8-12 years of experience, and more than 12 years of experience. Approximately one-fourth (23.9 percent) of the partici- 
pants had less than 4 years of experience as a counselor, 18.9 percent had 4-7 years of experience, 14.5 percent had 8-12 years of experience, and 42.8 had more than 12 years of experience.

Three-fourths (74.9 percent) of the participants indicated that they had completed a course in ethics or legal issues in counseling. Almost two-thirds (63.2 percent) of the respondents indicated that they had completed continuing education in ethics or legal issues in the past three years. More than one-half (60.3 percent) of the participants were licensed professional counselors, and 31.5 percent were certified by NBCC.

\section{Survey}

In section 1 of the survey, the researchers focused on determining the specific legal issues being encountered by counselors and the prevalence of these issues. The legal issues addressed in the literature were listed on the survey (Corey, et al., 2003; Glosoff, Herlihy, \& Spence, 2000; Lawrence \& Kurpius, 2000; Remley \& Herlihy, 2001; White \& Flynt, 2000): determining whether to report suspected child abuse, being pressured to verbally reveal confidential information, being asked to turn over confidential records, determining whether a client posed a danger to others, determining whether a client was suicidal, and being subpoenaed to appear as a witness in a legal proceeding. In addition, the survey gave participants an opportunity to add other legal issues they had encountered in the past year and asked participants to indicate how many times they had encountered each of the legal issues in the past year.

In section 2 of the survey, the researchers presented the same legal issues and asked respondents to indicate how prepared they felt to respond to the legal issues. Participants responded via a Likert-type scale ranging from one to five (one indicating not prepared and five indicating very prepared).

In the final section of the survey, the researchers gathered information on the independent variables in this study. Variables identified in previous studies (Davis \& Mickelson, 1994; Gibson, 1992; Herndon, 1990; Rawls, 1997) as potentially related to counselors' knowledge of legal and ethical issues were included as independent variables in this study. Participants were asked whether they worked in school settings, whether they had taken a graduate course in ethics or legal issues in counseling, whether they had recently participated in continuing education in legal or ethical issues in counseling, their highest degree earned, whether they were licensed as professional counselors by their state, whether they were certified by NBCC, and their years of experience as a counselor.

To test the survey's content validity, five experts in legal issues in counseling provided feedback as to whether the survey identified the major legal issues being encountered by counselors. Additionally, 12 counselors who worked in school or community mental health settings completed a draft of the survey, indicating any problems they experienced with it and reporting the amount of time required to complete it. The feedback about the survey improved the survey's clarity and was used in preparing the final form of the survey.

\section{Procedure}

A cover letter and survey were mailed to the 1,000 prospective participants, with a self-addressed stamped envelope included in the packet to encourage response and to protect anonymity. To increase response rate, two weeks after mailing the packets a postcard was mailed to all potential participants to remind them that they had recently received the survey and to request that they complete and return it if they had not already done so. We analyzed the data from completed surveys through the use of descriptive statistics, independent $t$ tests, analysis of variance, and a wave analysis.

\section{Results}

\section{Legal Issues Encountered by Counselors}

Participants were asked to indicate the approximate number of times in the past year they had encountered the legal issues listed on the survey. Responses are summarized in Table 1. Determining whether a client was suicidal was the most prevalent legal issue encountered by counselors. Other prevalent legal issues were determining whether to report suspected child abuse and determining whether a client posed a danger to others. The legal issues encountered least often were being asked to turn over clients' records and being subpoenaed to appear as a witness in a legal proceeding.

The participants also indicated that they had dealt with some legal issues that were not included on the survey. One community mental health counselor added elder abuse as a legal issue, and another community mental health counselor encountered the issue of incapacitated adult abuse. Three school counselors and one community mental health counselor indicated they were asked to play a role in child custody proceedings. Three 
school counselors reported they had counseled students who had been sexually harassed by other students, and one school counselor had encountered a case of statutory rape. Another school counselor added minors' abortion rights to the legal issues presented on the survey. One school counselor reported facing legal issues related to the Family Educational Rights and Privacy Act of 1974 (FERPA). Seven school counselor participants indicated they had encountered legal issues related to special education laws. Finally, two school counselors reported they were threatened with lawsuits related to professional services, and one school counselor had been named as a defendant in a lawsuit for educational malpractice.

\section{Relationship Between Primary Practice Setting and Frequency of Legal Issues}

In this study, we explored whether primary practice setting was related to the types and frequency of legal issues encountered by counselors. The data indicated that counselors in both school settings and nonschool settings encountered all of the legal issues listed on the survey. Independent $t$ tests were used to determine whether significant differences existed in the number of times each legal issue listed on the survey was encountered during a 12-month period by school counselors and the number of times these issues were encountered in the same 12-month period by community mental health counselors. Differences were considered significant at the .05 level as iterated below. A Bonferroni procedure was used to adjust for the multiple $t$ tests and minimize the possibility of a Type I error.

According to these results, school counselors had to determine whether to report suspected child abuse ( $M=$ $3.39, S D=3.27$ ) statistically significantly more often $[t(434)=6.68, p<.05$, Cohen's $d=.64)]$ than community mental health counselors $(M=1.74, S D=1.90)$. However, mental health counselors were asked to turn over confidential records $(M=.83, S D=1.47)$ statistically significantly more often $[t(244)=3.60, p<.05, d=$ .46)] than school counselors $(M=.37, S D=.93)$. Counselors working in community settings also had to determine whether clients were suicidal $(M=7.50, S D=$ 11.55) significantly more often $[t(192)=3.92, p<.05, d$ $=.56)]$ than school counselors $(M=3.83, S D=4.27)$. All three of these tests yielded moderate effect sizes based on the measure of Cohen's $d$.

\section{Counselors' Perceived Level of Preparedness to Respond to Legal Issues}

Participants were asked to indicate the degree to which they felt prepared to respond to the legal issues listed on the survey. The survey presented a continuum from one

\begin{tabular}{|l|l|l|l|l|l|}
\hline Table 1. Mean Number of Times Participants Encountered Legal Issues in a 12-Month Period & \begin{tabular}{l} 
Encountered \\
Legal Issue \\
\hline Legal Issue
\end{tabular} & $\begin{array}{l}\text { Encountered } \\
\text { Two or More } \\
\text { Times }\end{array}$ & Range & Mean & $\begin{array}{l}\text { Standard } \\
\text { Deviation }\end{array}$ \\
\hline $\begin{array}{l}\text { Determining Whether to Report } \\
\text { Suspected Child Abuse }\end{array}$ & $81 \%$ & $64 \%$ & $0-30$ & 2.77 & 2.94 \\
\hline $\begin{array}{l}\text { Being Pressured to Verbally Reveal } \\
\text { Confidential Information }\end{array}$ & $49 \%$ & $33 \%$ & $0-25$ & 1.44 & 2.65 \\
\hline $\begin{array}{l}\text { Being Asked to Turn Over Confidential } \\
\text { Records }\end{array}$ & $26 \%$ & $14 \%$ & $0-10$ & .54 & 1.18 \\
\hline $\begin{array}{l}\text { Determining Whether a Client Posed } \\
\text { Danger to Others }\end{array}$ & $73 \%$ & $49 \%$ & $0-60$ & 2.50 & 5.22 \\
\hline $\begin{array}{l}\text { Determining Whether a Client Was } \\
\text { Suicidal }\end{array}$ & $90 \%$ & $77 \%$ & $0-60$ & 5.22 & 8.04 \\
\hline $\begin{array}{l}\text { Being Subpoenaed to Appear as a } \\
\text { Witness in a Legal Proceeding }\end{array}$ & $22 \%$ & $7 \%$ & $0-4$ & .33 & .74 \\
\hline
\end{tabular}


to five, one indicating that the participant did not feel prepared to deal with the issue and five indicating that the participant felt very prepared to deal with the issue. Responses of one and two were interpreted as poorly prepared, responses of three were interpreted as moderately prepared, and responses of four and five were interpreted as well prepared. The results of these data are summarized in Table 2.

The participants reportedly felt best prepared to determine whether to report suspected child abuse. Eighty-seven percent of the respondents indicated that they felt well prepared to make this determination. Furthermore, 77 percent of the participants indicated that they felt well prepared to determine whether a client was suicidal. Respondents indicated that they felt least confident in their ability to respond to a subpoena to appear as a witness in a legal proceeding. Only onefourth (26 percent) of the participants felt well prepared to respond to this issue, and almost one-half (47 percent) indicated that they felt poorly prepared to respond to a subpoena.

\section{Relationship of Variables to Perceived Degree of Preparedness to Respond to Legal Issues}

We sought to determine whether certain variables were related to the participants' perceived level of preparedness to respond to legal issues. These variables included primary practice setting, completion of a graduate course in ethics or legal issues in counseling, recently completing continuing education in ethics or legal issues, high- est degree earned, state licensure as a professional counselor, certification by NBCC, and years of experience as a counselor. Independent $t$ tests were used to determine whether significant differences existed in the participants' perceived degree of preparedness to respond to each legal issue based on these variables. Differences were considered significant at the .05 level. A Bonferroni procedure was used to adjust for the multiple $t$ tests and minimize the possibility of a Type I error. The results are summarized in Table 3.

\section{Primary Practice Setting}

Using independent $t$ tests, we compared the mean scores indicating degree of preparedness to respond to each legal issue listed on the survey for school counselors and for community mental health counselors. The results of the $t$ tests showed significant differences between the means of the two groups in degree of preparedness to respond to five of the six legal issues on the survey, with small to moderate effect sizes. Community mental health counselors reported feeling better prepared than school counselors to respond to all of the legal issues on the survey except determining whether to report suspected child abuse.

School counselors $(M=3.64, S D=1.07)$ reported feeling significantly less prepared to deal with pressure to verbally reveal confidential information $[t(433)=3.31, p$ $<.05, D=.32$, effect size $r=.16$ ] than did community mental health counselors $(M=3.99, S D=1.08)$. Similarly, counselors in school settings $(M=3.45, S D=$

\begin{tabular}{|c|c|c|c|c|c|}
\hline Legal Issue & $\begin{array}{l}\text { Poorly } \\
\text { Prepared }\end{array}$ & $\begin{array}{l}\text { Moderately } \\
\text { Prepared }\end{array}$ & $\begin{array}{l}\text { Well } \\
\text { Prepared }\end{array}$ & $M$ & $S D$ \\
\hline $\begin{array}{l}\text { Determining Whether to Report } \\
\text { Suspected Child Abuse }\end{array}$ & $3 \%$ & $10 \%$ & $87 \%$ & 4.34 & .78 \\
\hline $\begin{array}{l}\text { Being Pressured to Verbally Reveal } \\
\text { Confidential Information }\end{array}$ & $13 \%$ & $25 \%$ & $62 \%$ & 3.77 & 1.09 \\
\hline $\begin{array}{l}\text { Being Asked to Turn Over Confidential } \\
\text { Records }\end{array}$ & $18 \%$ & $24 \%$ & $58 \%$ & 3.61 & 1.15 \\
\hline $\begin{array}{l}\text { Determining Whether a Client Posed } \\
\text { a Danger to Others }\end{array}$ & $10 \%$ & $24 \%$ & $66 \%$ & 3.83 & .95 \\
\hline $\begin{array}{l}\text { Determining Whether a Client Was } \\
\text { Suicidal }\end{array}$ & $5 \%$ & $18 \%$ & $77 \%$ & 4.10 & .88 \\
\hline $\begin{array}{l}\text { Being Subpoenaed to Appear as a } \\
\text { Witness in a Legal Proceeding }\end{array}$ & $47 \%$ & $27 \%$ & $26 \%$ & 2.65 & 1.31 \\
\hline
\end{tabular}




\begin{tabular}{|l|l|l|l|l|l|l|}
\hline Table 3. Significant Differences in Perceived Degree of Preparedness to Respond to Legal Issues \\
\hline Variable & $\begin{array}{l}\text { Reporting } \\
\text { Suspected } \\
\text { Child Abuse }\end{array}$ & $\begin{array}{l}\text { Reveal } \\
\text { Confidential } \\
\text { Information }\end{array}$ & $\begin{array}{l}\text { Turn Over } \\
\text { Records }\end{array}$ & $\begin{array}{l}\text { Danger to } \\
\text { Others }\end{array}$ & $\begin{array}{l}\text { Danger to } \\
\text { Self }\end{array}$ & $\begin{array}{l}\text { Appear as } \\
\text { Witness }\end{array}$ \\
\hline Setting & No & Yes & Yes & Yes & Yes & Yes \\
\hline Course & Yes & No & No & Yes & No & No \\
\hline Cont. Ed. & Yes & Yes & Yes & Yes & Yes & Yes \\
\hline Degree & No & No & No & No & No & No \\
\hline Licensed & No & Yes & Yes & Yes & Yes & No \\
\hline Certified & No & No & No & No & No & No \\
\hline Yrs. of Exp. & No & No & No & Yes & No & No \\
\hline Level of Significance: Alpha .05 & & & & \\
\hline
\end{tabular}

1.18) were statistically significantly less prepared for the legal issue of being asked to turn over confidential records $[t(378)=3.98, p<.05, d=.41$, effect size $r=.20)]$ than were counselors in community settings $(M=3.88$, $S D=1.05)$. When ranking their preparedness to determine whether a client was a danger to self (suicidal) ( $M$ $=3.93, S D=.92)$, school counselors again scored significantly lower than their mental health colleagues $(M=$ $4.38, S D=.74)[t(432)=5.28, p<.05, D=.51$, effect size $r=.25]$. Mental health counselors reported feeling significantly more prepared to determine whether a client posed a danger to others $(M=4.04, S D=.88)$ than did school counselors $(M=3.70, S D=.98)[t(374)=3.78, p$ $<.05, D=.39$, effect size $r=.19$ ]. Finally, this trend continued with the legal issue of being subpoenaed to appear as a witness in a legal proceeding. The mean score of counselors in school settings $(M=2.49, S D=1.31)$ was significantly lower $[t(428)=3.38, p<.05, D=.33$, effect size $r=.16$ ] than the mean score of counselors in community settings $(M=2.92, S D=1.26)$.

\section{Course in Ethics or Legal Issues}

We used independent $t$ tests to compare the mean scores of reported preparedness to respond to legal issues of participants who took a course in ethics or legal issues and those who did not. The results showed significant differences between the two groups in reported degree of preparedness to determine whether to report suspected child abuse $(D=.29)$ and to determine whether a client posed a danger to others. In each instance, counselors who had completed a separate course in ethics or legal issues felt more prepared to address the legal issue, as demonstrated by the large effect size $(D=.81)$. Regarding determining whether to report suspected child abuse, the mean score of participants who took a course in ethics or legal issues ( $M=4.41, S D=.74$ ) was significantly higher $[t(431)=3.05, p<.05, D=.29$, effect size $r=.14]$ than the mean score of participants who did not take such a course $(M=4.15, S D=.86)$. Furthermore, for determining whether a client posed a danger to others, the mean score of participants who took a course in ethics or legal issues $(M=3.97, S D=.87)$ was significantly higher $[t(153)=5.01, p<.05, d=.81$, effect size $r$ $=.37]$ than that of participants who did not take such a course $(M=3.40, S D=1.07)$.

\section{Recently Completing Continuing Education in Ethics or Legal Issues}

For each legal issue listed on the survey, we used an independent $t$ test to compare the mean scores of participants who recently completed continuing education in ethics or legal issues and counselors who had not. These comparisons yielded significant differences in reported degree of preparedness to respond to all of the legal issues listed on the survey, with effect sizes ranging from .30 to .52 . In each instance, participants who had recently completed continuing education felt better prepared to address the legal issue.

Participants who recently completed continuing education in ethics or legal issues in counseling ( $M=$ $4.43, S D=.71$ ) felt significantly more prepared when determining whether to report suspected child abuse $[t(285)=2.85, p<.05, D=.34$, effect size $r=.17]$ than did those who did not receive such training $(M=4.20$, $S D=.86)$. Similarly, these continuing education participants $(M=3.92, S D=1.04)$ reported feeling significant- 
ly more prepared $[t(433)=3.93, p<.05, d=.38$, effect size $r=.18$ ] to deal with being pressured to verbally reveal confidential information than did their counterparts $(M=3.51, S D=1.11)$. They $(M=3.74, S D=1.12)$ also felt significantly more prepared to deal with being asked to turn over confidential records $[t(432)=3.16, p$ $<.05, D=.30$, effect size $r=.15$ ] than did their counterparts $(M=3.38, S D=1.17)$. They $(M=3.99, S D=.89)$ reported feeling more confident when determining whether a client posed a danger to others $[t(299)=4.66$, $p<.05, d=.54$, effect size $r=.26$ ] than did those who did not receive training $(M=3.55, S D=1.00)$. Regarding determining whether a client was suicidal, the participants who recently completed continuing education ( $M$ $=4.24, S D=.78)$ reported significantly higher levels of preparedness $[t(272)=4.32, p<.05, D=.52$, effect size $r=.25$ ] than the group not receiving continuing education $(M=3.85, S D=.99)$. They $(M=2.81, S D=1.33)$ also reported significantly higher preparedness $[t(428)=$ $3.36, p<.05, D=.32$, effect size $r=.16$ ] for being subpoenaed to appear as a witness in a legal proceeding than did their counterparts $(M=2.38, S D=1.22)$.

\section{Highest Degree Obtained}

In exploring the importance of level of education to reported degree of preparedness to respond to the legal issues on the survey, we compared the mean scores of the master's level practitioners with those who held a higher degree, using independent $t$ tests. No statistically significant differences were found.

\section{Licensure}

Using an independent $t$ test, we compared the mean score of participants who were licensed with that of participants who were not licensed across all the legal issues. These comparisons yielded significant differences. Participants who were licensed felt better prepared to respond to being pressured to verbally reveal confidential information, being asked to turn over confidential records, determining whether a client posed a danger to others, and determining whether a client was suicidal. In each instance, licensure had a powerful influence as demonstrated by effect sizes ranging from .34 to .50 .

Licensed counselors felt better prepared to deal with pressure to verbally reveal confidential information. The mean score of participants who were licensed $(M=3.96$, $S D=1.03)$ was significantly higher $[t(342)=4.65, p<$ $.05, D=.50$, effect size $r=.24$ ] than unlicensed participants $(M=3.47, S D=1.10)$. Again, when being asked to turn over confidential records, the licensed counselors
$(M=3.79, S D=1.09)$ reported feeling significantly more prepared to deal with the issue $[t(431)=4.12, p<.05, D$ $=.40$, effect size $r=.19]$ than did their counterparts $(M=$ 3.33, $S D=1.19$ ). Additionally, when determining whether a client posed a danger to others, they $(M=$ $3.94, S D=.91)$ reported feeling significantly more prepared $[t(344)=3.12, p<.05, D=.34$, effect size $r=.17]$ than did the participants who were not licensed $(M=$ $3.65, S D=.99)$. Similarly, the licensed counselors ( $M=$ $4.22, S D=.80$ ) reported feeling significantly more prepared when determining whether a client was suicidal, $[t(431)=3.56, p<.05, D=.34$, effect size $r=.17]$ than did unlicensed participants $(M=3.91, S D=.97)$.

\section{Certification}

We compared the mean scores of participants who were or were not certified by the National Board of Certified Counselors across all issues, using an independent $t$ test. These comparisons yielded no significant differences between the means of the two groups in reported degree of preparedness to respond to the legal issues.

\section{Years of Experience}

To compare the mean scores for preparedness on all of the legal issues of participants with less than 4 years of experience, 4-7 years of experience, 8-12 years of experience, and more than 12 years of counseling experience, we computed an analysis of variance. No statistically significant differences were found.

\section{Response Bias}

To assess response bias, we performed a wave analysis procedure. Creswell (2002) asserted that the key issue with return rate is not necessarily the number of respondents but whether the responses were biased and thus did not reflect the experiences of the population. Creswell noted that participants responding at the end of the study are most similar to nonrespondents. In this study, the first 20 returns were received in the first week of data collection, and the last 20 returns were received four to six months later. Because no statistically significant differences were found in responses from the first 20 returns and the last 20 returns, response bias was not indicated, and generalizability of these results was supported.

\section{Discussion}

The results of this study indicate that counselors are encountering legal issues in their counseling practice. These results can inform policymakers, researchers, and 
practitioners of the need for specialized training. Participants reported encountering all of the legal issues listed on the survey. Determining whether a client is suicidal, determining whether to report suspected child abuse, and determining whether a client poses a danger to others were the legal issues that participants reported encountering most frequently. Being asked to turn over confidential records and being subpoenaed to appear as a witness in a legal proceeding, as well as other issues, were encountered less frequently.

Differences appeared in the types of legal issues encountered and how frequently they occurred depending upon the counselors' primary practice setting. School counselors more often had to determine whether to report suspected child abuse, but community mental health counselors had to determine more frequently whether clients were suicidal. Community mental health counselors were also asked to turn over confidential records more often. Because this legal issue often coincides with being involved in litigation, these results indicate that community mental health counselors may be involved in court proceedings more often than school counselors. However, the three participants who reported being threatened with a lawsuit or named as a defendant in a lawsuit were school counselors. Due to these inconsistent findings, we suggest the need for further research.

Participants indicated that they felt more prepared to deal with some legal issues than others. Specifically, respondents felt most prepared to determine whether to report suspected child abuse and to determine whether a client was suicidal. Counselors felt least prepared to respond to a subpoena to appear as a witness in a legal proceeding. It is noteworthy that the legal issues faced most frequently are those that counselors are most comfortable facing. It may be that counselors develop confidence in dealing with legal issues that they face on a regular basis. Alternatively, counselors may receive more training on issues that occur more often.

We also found differences in level of preparedness to respond to legal issues on the basis of the setting in which counselors worked. Participants who worked in community settings felt better prepared than school counselors to respond to five of the six legal issues listed on the survey. In a similar study, Gibson (1992) found that school counselors had less confidence in their ethics beliefs than community mental health counselors. The results of our study echo Gibson's finding with larger effect sizes and indicate that school counselors felt less prepared to address legal issues than did their communi- ty counterparts, except for the issue of reporting suspected child abuse. Our results also support the findings of Davis and Mickelson (1994), who reported that school counselors responded in a legally appropriate manner to survey items related to mandatory child abuse reporting. Davis and Mickelson also found that school counselors were not as proficient at answering items on legal and ethical issues related to privacy, confidentiality, parents' right to information, and testing. Such data may have broad implications for educational policy.

In our study, school counselors reported that they felt reasonably prepared to determine whether students are suicidal. On a scale of one to five (one indicating not prepared and five indicating very prepared), school counselors had a mean score of 3.93. This finding does not support the literature on this issue. Rawls (1997) noted that school counselors experienced difficulty with the legal issue of counseling suicidal students. Furthermore, King, Price, Telljohann, and Wahl (1999) found that only 38 percent of high school counselors felt that they could determine whether a student was at risk for committing suicide. This discrepancy merits additional investigation.

Gibson (1992) found a positive relationship between counselors' confidence in their ethics beliefs and the amount of instruction they had had in ethics. Similarly, Rawls (1997) reported a significant relationship between knowledge and training about school law with a large effect size $(d=.73)$. The results of our study also indicate that participants with instruction in ethics or legal issues in counseling felt better prepared to respond to certain legal issues.

One of the most important findings of our study is the importance of continuing education related to ethics or legal issues in counseling. Participants reporting recent training in these issues felt better prepared than their colleagues to respond to every legal issue listed on the survey. Considering these findings, it is notable that more than one-third (36.3 percent) of the participants had not participated in continuing education in legal and ethical issues in the past three years. This is a policy issue that needs to be addressed.

Counselors' reported level of preparedness to respond to legal issues did not differ significantly on the basis of years of experience or degree held. Similarly, King et al. (1999) found that counselors' confidence in their ability to identify students at risk for suicide did not differ significantly based on years of experience as a high school counselor or education level. Yet, Gibson (1992) found a positive relationship between counselors' confi- 
dence in their ethics beliefs and counselors' highest degree obtained $\left(\eta_{\mathrm{p}}^{2}=.02\right)$. Additionally, Rawls (1997) found significant differences in counselors' knowledge of legal issues according to counselors' level of education, with effect sizes ranging from small to medium. These conflicting results are worthy of future study.

In many states, school counselors are not required to be licensed as professional counselors. The results of this study indicate that school counselors are voluntarily becoming licensed as professional counselors. The sample consisted of 62.2 percent school counselors and 37.8 percent community mental health counselors, and 60.3 percent of the participants were licensed as professional counselors. Almost one-half (49.3 percent) of the school counselor participants reported that they were licensed professional counselors.

Our data also indicate that 20 (7.4 percent) of the 272 school counselor participants were members of AMHCA but not ASCA. Another 7 (2.6 percent) of the school counselor participants were members of both organizations. Thus, 27 (9.9 percent) of the 272 school counselor participants were members of AMHCA. These data support the conclusions of Paisley and McMahon (2001) regarding school counselors struggling with professional identity issues as they face increasing educational and mental health responsibilities.

Remley and Herlihy (2001) noted that malpractice lawsuits against mental health practitioners are increasing. However, they pointed out that the total number of lawsuits against mental health practitioners is still relatively small. Our research shows that the two legal issues likely to be indicative of involvement in litigation-being asked to turn over confidential records and being subpoenaed to appear as a witness in a legal proceedingwere encountered by participants least often. Although only 3 of the 437 participants indicated that they had been threatened with or named as a defendant in a lawsuit, such litigation could make or break a counselor's career. Therefore, important implications arise for both counselors and policymakers regarding preparedness to deal with legal issues.

Finally, legal challenges and dilemmas often present ethical challenges and dilemmas (Corey, et al., 2003; Remley \& Herlihy, 2001). Our research revealed ethical dimensionns to each issue listed. Thus, our results on prevalent legal issues illuminate ethical challenges currently facing practitioners. Most significantly, these results indicate that counselors are encountering ethical issues.

\section{Limitations}

One limitation of this study is that the sample consisted of counselors who were members of AMHCA or ASCA. Not all counselors are members of professional organizations. Members of professional organizations may have more access than nonmembers to professional literature and professional development activities. Thus, the counselors in this study may have been more knowledgeable about legal issues than counselors who are not members of AMHCA or ASCA.

Another limitation is that some universities have not taught ethics as a course but instead include discussions of legal and ethical issues in the courses they do offer. Accordingly, the counselors in this study may have had coursework that exposed them to legal and ethical issues in counseling, even though they did not take a specific course in these issues. This limitation may have affected the participants' responses related to the coursework in ethics or legal issues completed.

The study was further limited by the data-gathering potential of the survey, the self-report nature of the data, and the statistical procedures employed. For example, the use of the Likert-type scale to assess the degree to which counselors felt prepared to respond to legal issues limits the range of answers to the questions. Moreover, malpractice is a sensitive issue. Participants may have indicated they encountered fewer legal issues than they actually have and are better prepared to respond to legal issues than they actually are.

\section{Implications for Future Research}

According to Davis and Mickelson (1994), counselors' reports of having a good understanding of legal issues were not supported when their knowledge of those issues was tested. Thus, participants' reported degree of preparedness to respond to the issues addressed in our study could be inflated. Further study is warranted regarding the correlation between how prepared counselors feel to face legal issues and their actual knowledge of legal mandates. Similarly, valuable information can be gained from studies related to how counselors' knowledge of legal issues affects their confidence in responding to those issues. The correlation between the frequency with which counselors encounter legal issues and their level of confidence to respond to those issues is worthy of future study as well.

In some instances, the results of our study did not support previous research. For example, school counselors indicated that they felt reasonably well prepared to 
determine whether a client was suicidal. This finding is not supported by other studies (King, et al., 1999; Rawls, 1997). Furthermore, Gibson (1992) and Rawls both found that counselors' level of education was related to knowledge of and confidence in their knowledge of legal and ethical dictates, yet the results of our research did not support those findings. These conflicting results warrant further study of these issues.

Finally, counselors are facing numerous legal issues. Additional research considering the types and frequency of legal issues being encountered by counselors is needed. The most effective methods of training counseling students and counselors about how to practice in an ethically and legally sound manner are also worthy of future study.

\section{Implications for Policymakers}

Our findings point to the need for more rigorous training in ethical and legal issues in counseling programs. Specifically, training programs need to emphasize the legal and ethical standards endorsed by the American School Counselor Association (ASCA), the American Mental Health Counselors Association (AMHCA), and the American Counseling Association (ACA) regarding confidentiality of information in verbal and written form. School counselors need to know about Family Educational Rights and Privacy Act (FERPA) regulations and how to maintain and store confidential records. School counselors also need additional training on issues such as privacy, confidentiality, parents' right to information, and testing, as well the other issues presented in this study.

As our society becomes more litigious, counselors must be trained to deal with court proceedings. For example, specific training needs to be offered about how to respond to a subpoena, what a court order means, what must be revealed if a counselor is ordered to testify in a legal proceeding, and what must be protected. The Council for the Accreditation of Counseling and Related Educational Programs (CACREP) now requires that counseling programs they accredit offer coursework in ethics. Individual programs need to make sure they are covering all the ethical and legal issues that this research demonstrates counselors are missing.

Our study found that continuing education in legal issues was a significant factor in counselors' preparedness to deal with these issues. States regulate the continuing education required for counselors to maintain licensure. In addition, state and national counseling organiza- tions provide continuing education opportunities. Most conferences for counseling associations now systematically offer ethical and legal continuing education. These organizations may need to develop more extensive opportunities for counselors to learn about the issues they encounter less frequently. It is imperative that policymakers and leaders who plan these offerings make sure the trainings are practical and applicable to realworld scenarios.

\section{Implications for Practitioners}

This study's identification of the legal issues counselors are currently encountering can help counselors become aware of specific areas of legal vulnerability. We found that the most prevalent legal issue being encountered by counselors is determining whether a client is suicidal. However, we also found that the participants in this study felt prepared to deal with this issue. It stands to reason that counselors are choosing to prepare themselves to deal with suicidal clients. It is obvious that this important issue merits continued attention.

Counselors also frequently have to determine whether to report suspected child abuse and whether clients pose a danger to others. The legal mandates related to these issues vary by state. Thus, counselors need to be knowledgeable about relevant state statutes and case law.

A significant finding of our study is that counselors who recently participated in continuing education in ethics or legal issues in counseling felt better prepared than their colleagues to respond to every legal issue on the survey. However, more than one-third of the respondents did not take part in continuing education in these issues. Continuing legal education is particularly valuable to counselors because laws are constantly changing as new legal precedents and statutory law emerge. Our study's findings should encourage counselors to participate in continuing education on legal and ethical issues.

Finally, our study confirmed that counselors are encountering legal issues in their professional practice. In our litigious society, there is always a risk of being named a defendant in a lawsuit. Accordingly, it is imperative that counselors maintain adequate malpractice insurance if they are not adequately covered at their practice site. Counselors can also minimize the risk that they will be sued for malpractice by keeping current on legal issues in counseling through continuing education, consulting with colleagues on clinical issues, and consulting attorneys on legal issues. 


\section{References}

Ahia, C. E., \& Martin, D. (1993). The danger-to-self-orothers exception to confidentiality. Alexandria, VA: American Counseling Association.

Corey, G., Corey, M. S., \& Callanan, P. (2003). Issues and ethics in the helping professions (5th ed.). Pacific Grove, CA: Brooks/Cole.

Creswell, J. W. (2002). Educational research: Planning, conducting, and evaluating quantitative and qualitative research. Upper Saddle River, NJ: Pearson Education.

Davis, J. L., \& Mickelson, D. J. (1994). School counselors: Are you aware of ethical and legal aspects of counseling? The School Counselor, 42, 5-13.

Family Educational Rights and Privacy Act of 1974 (FERPA), 20 U.S.C. \& $1232 \mathrm{~g}$ (1982).

Fernandez, S. M. (1992). School counselor liability: A growing juggernaut (Educational Specialist thesis, Central Missouri State University, 1992).

Dissertation Abstracts International, 31-02, 524.

Gibson, W. T. (1992). Ethics beliefs of national certified counselors (Doctoral dissertation,University of Wyoming, 1992). Dissertation Abstracts International, 53-09A, 3108.

Glosoff, H. L., Herlihy, B., \& Spence, E. B. (2000). Privileged communication in the counselor-client relationship. Journal of Counseling \& Development, 78, 454-462.

Herndon, E. H. (1990). Legal aspects of the role of the public school counselor in North Carolina (Doctoral dissertation, University of North Carolina, Greensboro, 1990). Dissertation Abstracts International, 51-09A, 2985.

King, K. A., Price, J. H., Telljohann, S. K., \& Wahl, J. (1999). How confident do high school counselors feel in recognizing students at risk for suicide? American Journal of Health Behavior, 23, 457-467.

Lawrence, G., \& Kurpius, S. E. (2000). Legal and ethical issues involved when counseling minors in nonschool settings. Journal of Counseling $\mathcal{E}$ Development, 78, 130-136.

Paisley, P. O., \& McMahon, G. (2001). School counseling for the 21st century: Challenges and opportunities. Professional School Counseling, 5, 106-115.
Rawls, R. K. (1997). Virginia high school counselors and school law (Doctoral dissertation, Virginia Polytechnic Institute and State University, 1997). Dissertation Abstracts International, 58-08A, 3024.

Remley, T. P., Jr., \& Herlihy, B. (2001). Ethical, legal, and professional issues in counseling. Upper Saddle River, NJ: Prentice Hall.

White, J., \& Flynt, M. (2000). The school counselor's role in prevention and remediation of child abuse. In J. Wittmer (Ed.), Managing your school counseling program: K-12 developmental strategies ( $\mathrm{pp}$. 149-160). Minneapolis, MN: Educational Media.

IJEPL is a joint publication of the Association for Supervision and Curriculum Development, the Faculty of Education at Simon Fraser University, and the College of Education and Human Development at George Mason University. By virtue of their appearance in this open access journal, articles are free to use, with proper attribution, in educational and other non-commercial settings 90 days after initial publication. Copyright for articles published in IJEPL is retained by the authors. More information is available on the IJEPL Web site: http://www.ijepl.org 